\title{
Effect of Conditions at Germination and Nursery Stages on Fresh Weight of Plantlet and Leaf Weight at Harvest in Lactuca sativa L. cv. Greenwave
}

\author{
Shunsuke CHIBA and Hiroshi SHImizu* \\ School of Agriculture, Ibaraki University, 3-1-21-1, Ami, Ibaraki 300-0393, Japan \\ * Graduate School of Agriculture, Kyoto University Kitashirakawa-Oiwakecho, \\ Sakyo-ku, Kyoto 606-8502, Japan
}

(Received May 23, 2008)

\begin{abstract}
Leaf lettuce (Lactuca sativa L. cv. Greenwave) was grown in combinatory environments of electric conductivity (EC) of nutrient solution and photosynthetic photon flux (PPF) to investigate their influence on fresh weight and leaf area in plantlet and fresh weight of leaf at harvest. The experiments were conducted under the combinations of three levels of EC, of 1.0, $2.0 \mathrm{dS} \mathrm{m}^{-1}$ and tap water and three levels of PPF of 50,100 and $150 \mu \mathrm{mol} \mathrm{m}^{-2} \mathrm{~s}^{-1}$ to examine fresh weight and leaf area of plantlet. Although PPF had no influence on fresh weight grown in tap water, fresh weight significantly increased as PPF increased in nutrient solution of EC 1.0 and $2.0 \mathrm{dS} \mathrm{m}^{-1}$. Leaf area cultured in tap water decreased as PPF increased, however leaf area greatly increased as PPF increased in nutrient solution of EC 1.0 and $2.0 \mathrm{dS} \mathrm{m}^{-1}$. Plantlet grown under two levels of nutrient solution as tap water and EC $1.0 \mathrm{dS} \mathrm{m}^{-1}$ and three levels of PPF 50, 100 and $150 \mu \mathrm{mol}$ $\mathrm{m}^{-2} \mathrm{~s}^{-1}$ were transplanted to hydroponic system with EC $2.0 \mathrm{dS} \mathrm{m}^{-1}$, PPF $200 \mu \mathrm{mol} \mathrm{m}^{-2} \mathrm{~s}^{-1}$, photoperiod $14 \mathrm{~h}$ and temperature $24^{\circ} \mathrm{C}$ to investigate the effect of condition at germination and raising seedling stages on fresh weight at harvest. Fresh weight of leaf lettuce showed similar tendency as fresh weight of plantlet, and it was found that EC of nutrient solution and PPF at the stage of germination and raising seedling significantly influenced fresh weight at harvest.
\end{abstract}

Keywords : electric conductivity, fresh weight, germination, leaf area, Lettuce (Lactuca sativa L.), raising seedling

\section{INTRODUCTION}

Plant factory has the advantage that it can produce high quality agricultural products stably in a planned manner, however, the initial and the running costs weigh on management, and these reductions are one of the issues. One of the methods of running cost reduction is shortening of a cultivation period, and many researches have been reported on influence of environmental conditions on plant growth to try to grope for the solution.

In this project, we paid our attention to nursery stage. Many of commercial facilities for lettuce production use tap water for nursery stage because the seed has required nutrition in the inside. Does the seed have enough nutrients over the nursery stage? The objective of this project was to examine the influence of the electrical conductivity (EC) of the culture solution and photosynthetic photon flux (PPF) during the nursery stage on fresh weight at harvest.

Corresponding author: Hiroshi Shimizu, fax : +81-75-753-6171, e-mail : hshimizu@kais.kyoto-u.ac.jp 


\section{MATERIALS AND METHODS}

The experiment was conducted by dividing into two parts. The first experiment (Exp. 1) evaluated the influence of nursery environments on the fresh weight and leaf area of lettuce at the end of nursery stage which was the seventh day after sowing. The second experiment (Exp. 2) investigated the influence of the conditions of nursery stage on the fresh weight at harvest which was the 30th day after transplant. Detail of each experiment was described below.

Exp.1: The influence of nursery environments on the fresh weight and leaf area at the end of nursery stage.

A growth chamber (M-20LTH, Koito, Tokyo, Japan) was used for nursery and was installed with three cultivation shelves. Two or more fluorescence lamps (EFG25EDG25W, Matsushita Electric Works, Tokyo, Japan) were added to each shelf. PPF was measured with a light quantum sensor (LI-190, LI-COR, Lincoln, NE, USA), and number of the fluorescent lamps and distance between the lamp and the shelf surface were adjusted so that PPF became 50,100, and $150 \mu \mathrm{mol}$ $\mathrm{m}^{-2} \mathrm{~s}^{-1}$ in each shelf.

Nine plastic trays (W: $32 \times$ D: $22.5 \times \mathrm{H}: 6 \mathrm{~cm}$ ) were prepared, and the first 3 trays were filled with 1 liter tap water, the second 3 trays were filled with 1 liter EC $1.0 \mathrm{dS} \mathrm{m}^{-1}$ of Otsuka "A" prescription (Otsuka, Tokyo, Japan), and the last 3 trays were filled with 1 liter EC $2.0 \mathrm{dS} \mathrm{m}^{-1}$ of Otsuka A prescription. Forty blocks of urethane cubes for hydroponics were put into each tray and leaf lettuce (Lactuca sativa L. cv. Greenwave) (Takii, Kyoto, Japan) was sown to each one block. Three trays of each concentration were put into the same shelf of the growth chamber. Temperature was set at $24^{\circ} \mathrm{C}$. The factors and levels of the experiment were indicated in Table 1 .

After 7 days, the image of each seedling was captured from the upper part, and the leaf area was calculated. A digital camera (C-3040Zoom, Olympus) was fixed to a camera stand at the position of $73.5 \mathrm{~cm}$ from the base surface of the stand. Even when the leaf had an angle to the camera, the posture of the leaf was not compulsorily changed. Therefore the captured image was a projection image. However, when the leaf was caught in the cut of a urethane cube, the leaf was taken out from the urethane by hand. Leaf area was calculated from the captured image using a image analysis software (Lia for Win32). The seedling after capturing image was carefully pulled out from the urethane cube, and fresh weight including a root was measured with an electronic balance (IB-200H, Iuchiseieido, Tokyo, Japan).

\section{Exp.2: The influence of nursery environments on fresh weight of lettuce at harvest.}

A $6 \mathrm{~m}$ hydroponics system was installed indoors, and $32 \mathrm{Hf}$ fluorescent tubes (FHF32X-NH,32W, Matsushita Electric Works, Tokyo, Japan) which was able to control light intensity were arranged to $50 \mathrm{~cm}$ above the cultivation panel. The circumference of a hydroponics system was covered with lightproof curtain from a ceiling to avoid the influence by the change of temperature and light conditions in the room. An air-conditioner (RAV-161JD, Hitachi, Tokyo, Japan) was installed inside the lightproof curtain, and temperature was maintained at $24^{\circ} \mathrm{C}$. PPF at the cultiva-

Table 1 Environmental factors and levels.

\begin{tabular}{ll}
\hline \multicolumn{1}{c}{ Factor } & \multicolumn{1}{c}{ Level } \\
\hline $\begin{array}{l}\text { Photosynthesis Photon Flux } \\
\text { Culture solution }\end{array}$ & $50,100,150 \mu \mathrm{mol} \mathrm{m}^{-2} \mathrm{~s}^{-1}$ \\
& Tap water, EC1.0 dS m ${ }^{-1}, \mathrm{EC} 2.0 \mathrm{dS} \mathrm{m}^{-1}$ \\
\hline
\end{tabular}


tion panel was set at $200 \mu \mathrm{mol} \mathrm{m}{ }^{-2} \mathrm{~s}^{-1}$ using an HF light controller (NQ21572 321, Matsushita Electric Works, Tokyo, Japan), and photoperiod was set in $14 \mathrm{~h}$ with a timer (H2F-DF, Omron, Kyoto, Japan). Culture solution was Otsuka "A" prescription adjusted EC $2.0 \mathrm{dS} \mathrm{m}{ }^{-1}$. The seedlings after nursery stage were transplanted to this hydroponics system, and grown for 30 days, and then fresh weight and number of leaves were measured.

\section{RESULTS AND DISCUSSION}

\section{Exp.1: The influence of nursery environments on the fresh weight and leaf area at the end of nursery stage.}

The result of measurement of fresh weight and leaf area is shown in Figs. 1 and 2. The fresh weight of the seedling in tap water was about $0.02 \mathrm{~g}$, and not changed though PPF increased. On the other hand, it was found that fresh weight in EC1.0 and 2.0 was about $0.6 \mathrm{~g}$ at relatively low PPF of $50 \mu \mathrm{mol} \mathrm{m} \mathrm{m}^{-2} \mathrm{~s}^{-1}$. It was almost three times as much as tap water, and fresh weight in EC1.0 and 2.0 increased as PPF increased. The difference of the fresh weight by PPF was investigated in tap water and each culture solution concentration. The homogeneity of variance of the data between PPF in each solution was investigated by the Bartlett test. As a result, variance differed by $1 \%$ of a significance level by EC1.0 dS m${ }^{-1}$, and it turned out that variance was equal in tap water and EC2.0 dS m${ }^{-1}$. Then ANOVA test was applied to the data of tap water and EC2.0 dS m${ }^{-1}$, and Kruscal-Wallis was performed to the data EC1.0 dS m ${ }^{-1}$. The result was shown in Table 2.

In tap water, P value was set to 0.054 and the significant difference to PPF was not found. On the other hand, in EC1.0 and EC2.0, P value all became 0.01 or less, and significant differences to PPF were highly shown.

In Fig. 1, the fresh weight in EC1.0 and $2.0 \mathrm{dS} \mathrm{m}^{-1}$ showed the almost same increase with the increase in PPF, then the effect of culture solution on the fresh weight of lettuce was investigated next. Since it became clear that homogeneity of variance was found by the Bartlett test, $t$-test was performed to examine the difference between them. The result was shown in Table 3. From this table, there was no significant difference in 50 and $100 \mu \mathrm{mol} \mathrm{m}^{-2} \mathrm{~s}^{-1}$, however the significant difference was found by the level of 0.05 in $150 \mu \mathrm{mol} \mathrm{m}^{-2} \mathrm{~s}^{-1}$.

Figure 2 shows the measured leaf area of seedlings at the end of the nursery stage which was the seventh day after sowing. The leaf area had the almost same tendency as the case of fresh weight. The leaf area in tap water did not change as PPF increased, on the other hand, the leaf area in EC1.0 and $2.0 \mathrm{dS} \mathrm{m}^{-1}$ increased as PPF increased. The same procedure as the case of fresh

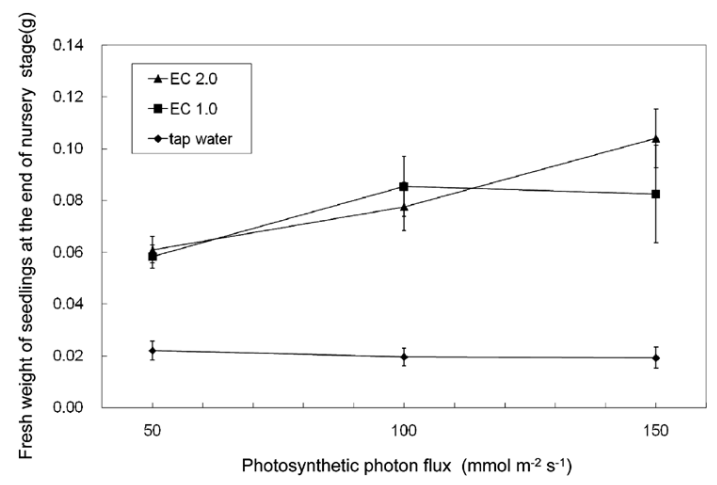

Fig. 1 Effect of EC of nutrient solution and PPF on fresh weight of seedlings at the end of nursery stage. Bars represent $\mathrm{SD}$. 


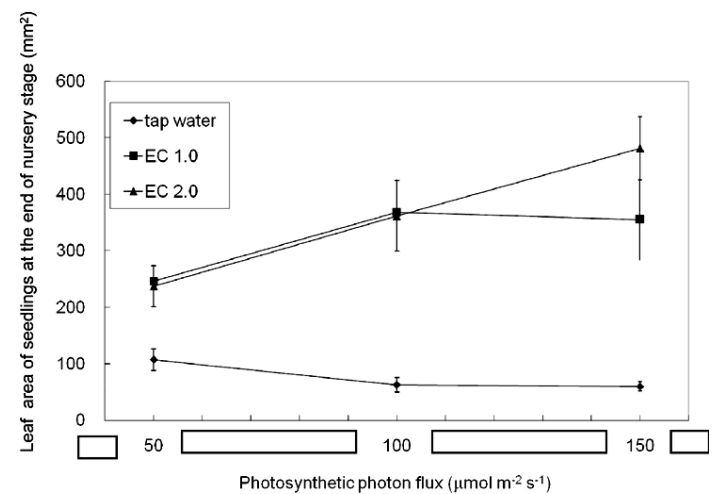

Fig. 2 Effect of EC of nutrient solution and PPF on leaf area of seedlings at the end of nursery stage. Bars represent $\mathrm{SD}$.

Table 2 Effect of PPF on fresh weight of seedlings after nursery stage. The data of tap water and EC2.0 were applied to ANOVA test and EC1.0 was Kruskal-Wallis test. Mean $\pm \mathrm{SD}$

\begin{tabular}{ccccc}
\hline \multirow{2}{*}{ Factor } & \multicolumn{4}{c}{ PPF } \\
\cline { 2 - 4 } & 50 & 100 & 150 & $P$ \\
\hline Tap Water & $0.022 \pm 0.0036$ & $0.019 \pm 0.0033$ & $0.019 \pm 0.0039$ & 0.054 \\
EC1.0 & $0.058 \pm 0.0042$ & $0.085 \pm 0.011$ & $0.083 \pm 0.017$ & $<0.01$ \\
EC2.0 & $0.061 \pm 0.0048$ & $0.078 \pm 0.0089$ & $0.104 \pm 0.011$ & $<0.01$ \\
\hline
\end{tabular}

ANOVA table

\begin{tabular}{ccccccc}
\hline Subject & Factor & SS & df & MS & F value & $P$ value \\
\hline \multirow{4}{*}{ Tap water } & PPF & $9.06 \mathrm{E}-05$ & 2 & $4.53 \mathrm{E}-05$ & 3.23218 & 0.0536 \\
& Error & 0.00042 & 30 & $1.4 \mathrm{E}-05$ & & \\
& Total & 0.000511 & 32 & & & $<0.01$ \\
\hline \multirow{3}{*}{ EC 2.0 } & PPF & 0.009797 & 2 & 0.004898 & 62.06646 & \\
& Error & 0.002289 & 29 & $7.89 \mathrm{E}-05$ & & \\
& Total & 0.012086 & 31 & & & \\
\hline
\end{tabular}

Kruskal-Wallis test

\begin{tabular}{cccc}
\hline Subject & $\chi^{2}$ value & df & $P$ value \\
\hline EC 1.0 & 15.8754 & 2 & $<0.01$ \\
\hline
\end{tabular}

weight investigated the effect of PPF in each culture solution. The Bartlett test was performed to investigate homogeneity of variance, and it was clear that the variance was not equal only in the case of tap water. Then, the Kruscal-Wallis test (Kanji, 1993) was carried out for the data of tap water and ANOVA test was applied to the data of EC1.0 and $2.0 \mathrm{dS} \mathrm{m}^{-1}$. The result was shown in Table 4. There was the significant difference in all culture solutions by PPF. Moreover, the culture solution of EC1.0 and 2.0 examined whether there was a significant difference in each PPF by $\mathrm{t}$ test on the leaf area. There was not significant difference in PPF of 50 and $100 \mu \mathrm{mol} \mathrm{m}^{-2} \mathrm{~s}^{-1}$, in contrast, the significant difference was found in PPF of $150 \mu \mathrm{mol} \mathrm{m}^{-2} \mathrm{~s}^{-1}$ (Table 5), and the similar result as the case of fresh weight was obtained. From these results, comparing the case to use only tap water and the case to use the culture solution in germination and nursery stage, the influences that PPF had on the morphological characteristics of lettuce seedlings differed greatly. In tap water, even if PPF increased, the fresh weight of the seedling did not change but leaf area decreased. On the other hand, in culture solution, fresh weight and leaf area also increased notably, and it became clear that fresh weight and leaf area become heavier and larger when EC of culture 


\section{CONDITIONS AT GERMINATION}

Table 3 Result of $t$-test on difference between fresh weight under the same PPF conditions about EC1.0 and EC2.0.

\begin{tabular}{cccc}
\hline PPF & 50 & 100 & 150 \\
\hline EC1.0 & $0.058 \pm 0.0045$ & $0.085 \pm 0.012$ & $0.0825 \pm 0.019$ \\
EC2.0 & $0.061 \pm 0.0051$ & $0.078 \pm 0.0093$ & $0.104 \pm 0.011$ \\
$P$ & 0.214 & 0.13 & 0.012 \\
& NS & NS & $*$ \\
\hline
\end{tabular}

Table 4 Effect of PPF on leaf area of seedlings at the end of nursery stage. The data of EC1.0 and EC2.0 were applied to ANOVA test and tap water was Kruskal-Wallis test.

\begin{tabular}{|c|c|c|c|c|c|c|}
\hline \multirow{2}{*}{ Factor } & \multicolumn{5}{|c|}{ 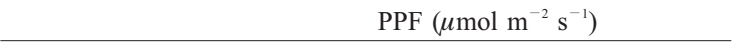 } & \multirow[b]{2}{*}{$P$} \\
\hline & \multicolumn{2}{|c|}{50} & 100 & \multicolumn{2}{|c|}{150} & \\
\hline Tap Water & \multicolumn{2}{|c|}{$107.5 \pm 18.2$} & $62.8 \pm 11.8$ & \multicolumn{2}{|c|}{$60.2 \pm 8.0$} & $<0.01$ \\
\hline EC1.0 & \multicolumn{2}{|c|}{$246.3 \pm 27.3$} & $368.1 \pm 53.6$ & \multicolumn{2}{|c|}{$355.4 \pm 65.7$} & $<0.01$ \\
\hline $\mathrm{EC} 2.0$ & \multicolumn{2}{|c|}{$237.4 \pm 35.3$} & $361.5 \pm 59.6$ & \multicolumn{2}{|c|}{$481.5 \pm 53.4$} & $<0.01$ \\
\hline \multicolumn{7}{|c|}{ ANOVA table } \\
\hline Subject & Factor & SS & $\mathrm{df}$ & MS & F value & $P$ value \\
\hline \multirow{3}{*}{ EC 1.0} & $\mathrm{PPF}$ & 72077.96 & 2 & 36038.98 & 12.99064 & $<0.01$ \\
\hline & Error & 52710.31 & 19 & 2774.227 & & \\
\hline & Total & 124788.3 & 21 & & & \\
\hline \multirow{3}{*}{ EC 2.0} & PPF & 369056.8 & 2 & 184528.4 & 69.30258 & $<0.01$ \\
\hline & Error & 87867.41 & 33 & 2662.649 & & \\
\hline & Total & 456924.3 & 35 & & & \\
\hline
\end{tabular}

Kruskal-Wallis test

\begin{tabular}{cccc}
\hline Subject & $\chi^{2}$ value & df & $P$ value \\
\hline Tap water & 19.8147 & 2 & $<0.01$ \\
\hline
\end{tabular}

solution was higher in PPF of $150 \mu \mathrm{mol} \mathrm{m} \mathrm{m}^{-2} \mathrm{~s}^{-1}$.

\section{Exp. 2: The influence of nursery environments on fresh weight of lettuce at harvest.}

Next, the influence of difference of culture solution at nursery stage on the fresh weight at harvest was examined. Due to our equipment, the experiment was conducted by tap water and the culture solution of EC1.0 dS m${ }^{-1}$. The seedlings grown in the environmental condition described in the above mentioned experiment 1 , namely, six combinations of culture solution and PPF, were used. The result was shown in Fig. 3. The fresh weight of lettuce grown with tap water in their nursery stage did not change at harvest even though PPF at nursery stage was changed. On the contrary, it was found that the fresh weight with nutrient solution of EC1.0 dS m${ }^{-1}$ was increased at harvest as PPF during the nursery stage increased. It was examined whether there was statistically a significant difference about this result. Since homogeneity of variance was not found about the data with tap water, Kruscal-Wallis test was performed, and there was no effect of PPF on the fresh weight of lettuce at harvest (Table 6).

On the other hand, in the culture solution of EC1.0 dS m${ }^{-1}$, since homogeneity of variance was accepted, ANOVA test was conducted, and there was high significant. Furthermore, the multiple comparison for every experiment section was performed by the Sheffe method, and there were the highly significant difference between 50 and $100 \mu \mathrm{mol} \mathrm{m}^{-2} \mathrm{~s}^{-1}$, and 50 and $150 \mu \mathrm{mol} \mathrm{m}^{-2} \mathrm{~s}^{-1}$, and also significant difference between 100 and $150 \mu \mathrm{mol} \mathrm{m}^{-2} \mathrm{~s}^{-1}$ (Table 7).

In the environmental condition performed in this research, when seedlings were grown with 


\section{S. CHIBA AND H. SHIMIZU}

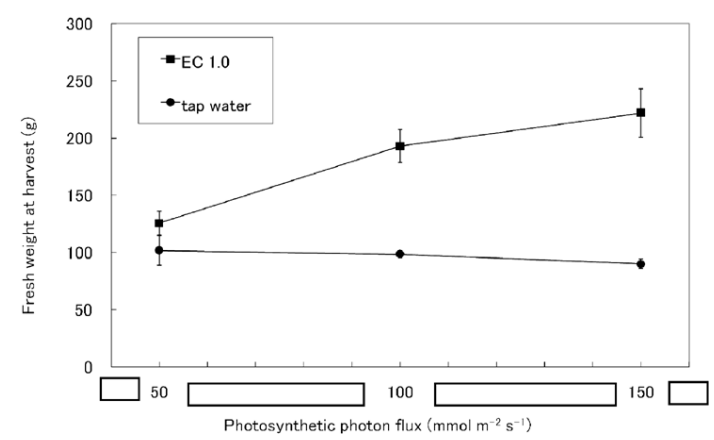

Fig. 3 Effect of EC of nutrient solution and PPF on fresh weight of seedlings at harvest. Bars represent SD.

Table 5 Result of $t$-test on difference between leaf area under the same PPF conditions about EC1.0 and EC2.0.

\begin{tabular}{cccc}
\hline PPF & 50 & 100 & 150 \\
\hline EC1.0 & $246.3 \pm 28.9$ & $368.1 \pm 57.9$ & $355.4 \pm 72.0$ \\
EC2.0 & $237.4 \pm 36.6$ & $361.5 \pm 62.5$ & $481.5 \pm 56.0$ \\
$P$ & 0.5479 & 0.8252 & $<0.01$ \\
& NS & NS & $* *$ \\
\hline
\end{tabular}

Table 6 Effect of PPF on fresh weight of lettuce crop at harvest. The data of EC1.0 was applied to ANOVA test and tap water was Kruskal-Wallis test.

\begin{tabular}{|c|c|c|c|c|c|c|}
\hline \multirow{2}{*}{ Factor } & \multicolumn{6}{|c|}{ PPF $\left(\mu \mathrm{mol} \mathrm{m}{ }^{-2} \mathrm{~s}^{-1}\right)$} \\
\hline & \multicolumn{2}{|c|}{50} & 100 & \multicolumn{2}{|c|}{150} & $P$ \\
\hline Tap Water & \multicolumn{2}{|c|}{$101.8 \pm 11.8$} & $98.5 \pm 2.8$ & \multicolumn{2}{|c|}{$90.0 \pm 3.5$} & 0.0812 \\
\hline EC1.0 & \multicolumn{2}{|c|}{$125.7 \pm 9.5$} & $193.0 \pm 13.1$ & \multicolumn{2}{|c|}{$221.8 \pm 19.4$} & $<0.01$ \\
\hline \multicolumn{7}{|c|}{ ANOVA table } \\
\hline Subject & Factor & SS & df & MS & $\mathrm{F}$ value & $\mathrm{P}$ value \\
\hline \multirow{3}{*}{ EC 1.0} & PPF & 29191.99 & 2 & 14595.99 & 57.07434 & $<0.01$ \\
\hline & Error & 3836.048 & 15 & 255.7365 & & \\
\hline & Total & 33028.04 & 17 & & & \\
\hline
\end{tabular}

Kruskal-Wallis test

\begin{tabular}{cccc}
\hline Subject & $\chi^{2}$ value & df & $P$ value \\
\hline Tap water & 5.0208 & 2 & 0.0812 \\
\hline
\end{tabular}

Table 7 Result of multiple comparison using Sheffe test on effect of PPF in nursery stage on fresh weight at harvest.

\begin{tabular}{ccccccc}
\hline Factor & Level 1 & Level 2 & Average 1 & Average 2 & Difference & $P$ value \\
\hline \multirow{4}{*}{ PPF } & 50 & 100 & 125.7 & 193.0 & 67.3 & $<0.01$ \\
& 50 & 150 & 125.7 & 221.8 & 96.1 & $<0.01$ \\
& 100 & 150 & 193.0 & 221.8 & 28.8 & 0.0237 \\
\hline
\end{tabular}

the culture solution of EC1.0 dS m${ }^{-1}$, the fresh weight and leaf area of the seedling became large as PPF increased, and also when these seedlings were grown on the same environmental condition, the relation that the fresh weight at harvest increased which had large fresh weight and leaf area in the nursery stage was suggested. Although it was reported that the influence of concentration of 
culture solution on growth of leafy vegetables (De Pinheiro Henriques et al., 2000, Maruo et al., 2002, Lee et al., 2006), there is little report that quantitatively considered the combinatorial influence of EC and PPF on the fresh weight at harvest paying attention to the environmental conditions of the nursery stage.

As a report of a germination and initial growth, Zhang and Hashinaga (1997) conducted the experiment to examine the effect of the high-voltage electric field on the growth of radish sprout for the purpose of the improvement in germination of leafy vegetables, and they reported that the average germination period was remarkably improved. In addition, it was confirmed that there was the positive effect for the stem elongation of the seedlings until the seventh day after sowing in the direct current electric field, and was negative in the alternating electric field. However, it was unknown what kind of influence occurred on the subsequent growth after nursery stage since Zhang and Hashinaga paid their attention to initial growth.

Miyajima (1994) examined the influence of concentration of culture solution on the growth of Brassica rapa var. perviridis, and reported that ascorbic acid in a leaf and the concentration of sugar increased when grown in the lower concentration of culture solution. However, the relation with the quality of the seedlings was not clear since this experiment covered all the cultivation period.

Although it was not leafy vegetables, Teragishi et al. (1998) evaluated that the quality of ficus seedlings from the shoot length, the number of leaves, the color of leaves, the chlorophyll content and so on, and examined the influence of the quality of seedlings on the yields of fruits and sugar content.

Thus, since there are few reports of the influence of the concentration of culture solution and PPF in the nursery stage of lettuce on the fresh weight at harvest, it was not able to discuss the result of this research comparing the past reports. However, we think that the result of this research quantitatively showed that it was effective to use nutrient solution during the nursery stage of leaf lettuce (Lactuca sativa L.cv. Greenwave) on enhancing the fresh weight at harvest.

\section{REFERENCES}

De Pinheiro Henriques, A. R., Marcelis, L. F. M. 2000. Regulation of growth at steady-state nitrogen nutrition in lettuce (Lactuca sativa L.): Interactive effects of nitrogen and irradiance. Ann. Bot. 86: 1073-1080.

Kanji, G. K. 1993. 100 Statistical Tests. SAGE Publications, London, pp 89.

Maruo, T., Shinohara, Y., Iwata, M., Ito, T. 2002. Effects of nutrient concentration on the absorption of N, $\mathrm{P}$ and $\mathrm{K}$ by lettuce cultured in NFT system (In Japanese with English summary). J. Japan. Soc. Hort. Sci. 71: $675-682$.

Lee, J. G., Lee, B. Y., Lee, H. J. 2006. Accumulation of phytotoxic organic acids in reused nutrient solution during hydroponic cultivation of lettuce (Lactuca sativa L.). Sci. Hortic. 110: 119-128.

Miyajima, D. 1994. Effects of concentration of nutrient solution, plant size at harvest and light condition before harvest on the ascorbic acid and sugar concentrations in leaves of hydroponically grown Komatsuna (Brassica campestris L. rapifera group). J. Japan. Soc. Hort. Sci. 63: 567-574.

Teragishi, A., Kanbara, Y., Ono, H. 1998. Comparison between phytotron - and glass house - propagated fig (Ficus carica L.) trees grown under similar solution culture on subsequent fruiting, plant growth, and fruits quality. J. Japan. Soc. Hort. Sci. 67: 715-720.

Zhang, H., Hashinaga, F. 1997. Effect of high electric fields on the germination and early growth of some vegetable seeds. J. Japan. Soc. Hort. Sci. 66: 347-352. 